\title{
IGUALDADE DE GÊNEROS: CONCEPÇÕES TRADICIONAIS, RESISTÊNCIA E AVANÇOS NAS RELAÇÕES ENTRE OS GÊNEROS
}

\section{ARTIGO ORIGINAL}

EPIFÂNIO, João Lazaro ${ }^{1}$

EPIFÂNIO, João Lazaro. Igualdade de gêneros: Concepções tradicionais, resistência e avanços nas relações entre os gêneros. Revista Científica Multidisciplinar Núcleo do Conhecimento. Ano 05, Ed. 11, Vol. 16, pp. 76-92. Novembro de 2020. ISSN: 2448-0959, Link de acesso: https://www.nucleodoconhecimento.com.br/educacao/igualdade-de-generos

\section{RESUMO}

Este estudo tem como preocupação básica refletir sobre a igualdade de gêneros, frente aos desafios das relações de igualdade entre os gêneros, desafios estes advindos das concepções tradicionais e das lutas de resistência por ocupação de espaços dos contingentes femininos. Este artigo tem como objetivo analisar a problemática da igualdade de gênero no contexto das concepções tradicionais, lutas feministas e a relação entre os gêneros, diante ao enfrentamento das formas de opressão a que são submetidos o gênero feminino. $O$ estudo foi realizado por meio de uma pesquisa bibliográfica considerando as contribuições de Fischer e Marques (2001); Gebara (2001): Antunes (1999); Oliveira (2001) e outros, procurando enfatizar os fatores que historicamente contribuíram para a formação de uma mentalidade que deu origem a uma sociedade desigual, onde as mulheres são oprimidas, sob a ótica da evolução tecnológica e da globalização. Concluiu que as relações de igualdade entre os gêneros ainda são orientadas pelas concepções tradicionais, embora os movimentos reacionários e a construção de novas relações tenham avançado a mentalidade machista ainda persiste na opressão ao gênero feminino.

\footnotetext{
1 Pós-Graduado em Psicopedagogia, Graduado em História.
} 
Palavras- Chave: Igualdade de gêneros, tradição, educação, relação.

\section{INTRODUÇÃO}

Este artigo procura refletir sobre a igualdade de gênero, tendo como preocupação a tradição, a luta e a construção das relações entre os gêneros, com vistas a elucidar as concepções formativas que embasam as práticas de exclusão do sexo feminino, fundamentalmente os fatores históricos, a mentalidade patriarcal e suas implicações no cenário educacional, social, político, cultural e econômico no contexto da evolução tecnológica do mundo globalizado.

Nessa perspectiva, para entender as formas de opressão é fundamental uma abordagem sobre os fatores históricos culturais com vista na mentalidade da sociedade patriarcal e suas implicações no contingente feminino das classes menos favorecidas, fatores étnicos e situação econômica. Nesse sentido construiu-se questões norteadoras para orientar o estudo: Como as relações de gênero são construídas no contexto sociocultural? A forma como estão estruturadas reflete as lutas feministas pela conquista de espaços?

Quando se aborda a questão de gênero pressupõe-se um sistema hierárquico vertical, propicio ao processo de submissão e opressão na relação entre os gêneros. Presumese assim, que a questão referente à igualdade de gênero é bastante complexa e abrange diversos fatores, que interligados, contribuem para uma situação opressora e de conflito.

Antunes (1999, p.109):

As relações entre gênero e classe nos permitem constatar que, no universo do mundo produtivo e reprodutivo, vivenciamos também a efetivação de uma construção social sexuada, onde os homens que trabalham são, desde a infância e a escola, diferentemente qualificados e capacitados para o ingresso no mundo do trabalho (...).

Nesse sentido, o objetivo deste artigo é, pois, analisar a problemática da igualdade de gênero no contexto das concepções tradicionais, lutas feministas e a relação entre os 
gêneros, frente ao enfrentamento das formas de opressão a que são submetidos o gênero feminino. No intuito de alcançar os objetivos utilizou-se como recurso metodológico a pesquisa bibliográfica, de cunho qualitativo, realizada a partir da análise pormenorizadas de materiais já publicados na literatura e artigo científicos divulgados nos meios eletrônicos.

O texto final foi fundamentado nas reflexões de autores como Fischer e Marques (2001); Pañuelos (2007); MMTR/RS (1995); Gebara (2001): Antunes (1999); Oliveira (2001), entre outros, que abordam a relação entre os gêneros no interior do contexto histórico e sociocultural e as formas de opressão que atingem os contingentes femininos.

Com a finalidade de elucidar o leitor, o texto foi dividido em seis partes, onde buscase fazer uma abordagem crítica e reflexiva acerca da igualdade de gênero, onde se constata que a classe feminina, tutelada pela classe masculina, encontra-se submetida a um processo opressivo, numa sociedade pensada a partir dos valores masculinos.

\section{FATORES TRADICIONALMENTE PRESERVADOS E ACEITOS PELA SOCIEDADE NO BRASIL}

A história dos povos e sua formação social, política, econômica, cultural, jurídica entre outras, reúnem um conjunto de fatores que expressam as ideias, os valores, a cultura concebidos, formados ou absorvidos, princípios éticos, concepções filosóficas, sociológicas, religiosas, ideológicas, culturais e, sobretudo biológicas que serviram de orientação para conduzir as sociedades na formação de conceitos sobre diferenças físicas, direitos conquistados, garantidos e/ou atribuídos segundo a natureza dos papeis ou funções desempenhadas por cada um dos membros integrantes da sociedade em que fazem parte, quais sejam, os gêneros masculino e feminino.

Desde os tempos mais remotos, homens e mulheres realizam atividades conforme suas capacidades e aptidões, observados os papeis que lhe foram atribuídos dentro dos primeiros grupos humanos, aceitos culturalmente ou impositivos e transmitidos de 
geração em geração como modelo na definição de funções desempenhados entre os gêneros e suas relações sociais. O domínio masculino se sobrepôs, levando em conta os aspectos físicos, principalmente no nomadismo onde a luta pela sobrevivência era o ponto fundamental da perpetuação dos grupos humanos. Nesse contexto, o gênero masculino teve melhor desempenho, seja na busca pelo alimento, na guerra ou nas tarefas que Ihes exigiam força física, capacidade de comando e liderança. Assim, se estabeleceram as relações de poder e domínio entre os gêneros.

Segundo Fischer e Marques (2001, p. 02), "As relações entre homens e mulheres, ao longo dos séculos, mantem caráter excludente. São assimiladas de forma bipolarizada, sendo designada à mulher a condição de inferior (...)". O homem na condição de ser racional se impõe aos mais fracos, sua capacidade de pensar associada às características biológicas foram determinantes para impor a ideia de inferioridade ao sexo oposto.

As concepções tradicionais tiveram forte influência na afirmação da superioridade masculina, tanto em termos biológicos quanto na condição de comando, de status e importância social. Na Grécia antiga é possível perceber forte influência das ideias plantonistas e aristotélicas da supremacia masculina, seja de cunho intelectual, estético, político, militar etc., colocando o ser mais frágil, no caso o gênero feminino, em situação de inferioridade. As concepções aristotélicas, aceitas na Idade Média e associadas ao pensamento religioso, reforçam a ideia de desigualdade entre os gêneros. Esse assertiva é tão verdadeira que a ideia de inferioridade do gênero feminino tornou-se um imperativo para a construção de uma mentalidade machista, aceita culturalmente sobre a desigualdade entre os gêneros. Ainda conforme Fischer e Marques (2001, p. 03) "A relação de gênero formada por homens e mulheres é norteada pelas diferenças biológicas, geralmente transformadas em desigualdades que torna o ser mulher vulnerável à exclusão social (...)". Essas concepções justificam a supremacia masculina, colocando em situação inferior o gênero feminino.

A construção de conceitos, que atribui ao sexo feminino o grau de inferioridade, se apoiam nas características físicas e orgânicas, biológicas e produtivas, as quais são vistas como critério de classificação quanto à capacidade de produzir, de se impor 
pela força e domínio, na relação de poder e na divisão de tarefas. Nesse sentido, o sexo feminino era visto como incapaz de realizar as mesmas atividades que o sexo oposto, principalmente com relação a periodicidade, ou mesmo que o sexo masculino, na condição de chefe assim definiu.

Conforme Pañuelos (2007), as tradições patriarcais presentes na língua que propende simplificar o sexo feminino, os modos utilizados e seus conteúdos vistos como um ato agressivo observado no cotidiano, tanto de forma individual quanto coletiva, ridicularizam o gênero feminino com expressões, conscientes ou inconscientemente, que estão carregadas de elementos machistas, discriminação e violência contra a mulher.

Associado a essa mentalidade ressoam as doutrinas religiosas criadas no contexto da Idade Média principalmente e, confirmada por narrativas criadas pelas elites, predominantemente masculinas, a fim de garantir seus privilégios, criando, inclusive leis que determinaram os direitos e deveres dos gêneros para assim exercerem seus papeis na sociedade. Nesse sentido, a desigualdade, entendida como normal, transcorreu por muito tempo sem que houvesse alguma sinalização de mudança, seguiu o curso da mentalidade elitizada, como elemento cultural aceito pela sociedade nos seus diversos seguimentos.

Observando o processo histórico verifica-se que é a parir da revolução industrial que a luta pela igualdade de direitos ganhou mais consistência, em função do tratamento desigual no trabalho nas fábricas. Ganhou fôlego também nos planos jurídico, político, social etc., devido ao processo de exploração a que eram submetidas no âmbito produtivo, principalmente nos países ocidentais, onde as revoluções (iluminismo, revoluções inglesas e francesa) ocorridas em datas posteriores já haviam apontado caminhos para uma sociedade mais justa e igualitária.

A formação de novos conceitos, em relação às mulheres, a construção de dispositivos jurídicos, em termos de diminuir a desigualdade, ascendência política entre outros aspectos, se devem principalmente ao desenvolvimento técnico/cientifico, cultural e econômico que possibilitou a formação de uma nova sociedade (modernidade) em 
face das exigências e necessidades do mundo moderno, demandada pela sociedade capitalista diante do mundo globalizado.

No entanto, o modelo de sociedade persistiu na adoção de conceitos excludentes que sempre colocaram em nível de inferioridade o sexo feminino, contribuindo para a sua marginalização, sendo vista até como condição humana, observada a situação econômica, social, cor e nascimento. De acordo MMTR/RS (1995), foi a partir do modelo de sociedade patriarcal que as diversas formas de opressão e exploração se intensificaram sobre o sexo feminino, criando raízes e se perpetuando entre os povos.

Sendo assim, percebe-se que são inúmeros os fatores que, tradicionalmente, justificam as narrativas de afirmação da desigualdade e sobreposição, em nível de exclusão, do gênero masculino para com o feminino, privando-o dos direitos de igualdade. Somando-se a esses existem outros que fortalecem os conceitos de desigualdade entre os gêneros, destacando-se o sentimento do domínio possessivo que, aliás, concebe o gênero feminino mais frágil, sensível e fisicamente subjugável. Gebara (2001), destaca que as mulheres, nessa visão de inferioridade são vistas como seres que pertencem a outros seres, a saber, os homens, assim, criaram-se a ideia de que as mulheres existem para servir aos homens. Ao gênero feminino são atribuídos desejo, paixão, prazer, portanto o sentimento de posse onde impera um tratamento conceituado na forma de objeto, o dominante atribui imposições e concebe o dominado como um objeto de manipulação.

Pelo exposto acima, é possível ter uma noção sobre as origens da desigualdade entre os gêneros, o que pode ser considerado o ponto de partida para a compreensão do processo de exclusão do sexo feminino e de vários aspectos relacionados a direitos e o longo percurso de luta pela igualdade. Essas concepções se sustentam no tradicionalismo cultural que ainda rege as sociedades e que concebe o sexo feminino como objeto de controle e manipulação. No entanto, fornece importante informação para a compreensão da sociedade que se formou a partir do século XXI, embora regida pelos valores do capitalismo e de alguns preceitos da religião e conceitos imbricados na mentalidade da cultura tradicional e conservadora. 


\section{O CONTEXTO FAVORÁVEL ÀS MUDANÇAS}

Diante das novas demandas do mundo moderno, intensificaram-se, principalmente no limiar do século XXI, as lutas pela liberdade em seus diversos aspectos e nos mais variados âmbitos de atuação: cultura, política, economia, educação, produção, esporte, trabalho, na dinâmica das relações sociais, no desempenho de altas funções nos mais diversos campos de atuação etc. Frente a esses novos desafios, surgem novas ideias e, consequentemente a mudanças de mentalidade, ambiente favorável que permitiu ao sexo feminino conquistar novos espaços na sociedade, porem vistos ainda como minoria. As novas ideias fortaleceram movimentos de classes, que cada vez mais ganharam expressividade, diante da dinâmica tecnológica e do desenvolvimento da ciência, bem como das novas exigências e necessidades do mundo moderno.

De acordo com Mota apud Duque, (2000, p.41), "a situação da mulher, nos últimos tempos vem se redefinindo, tomando novo vigor tanto nas relações sociais quanto na produção, sendo que essa reorganização provocou um equilíbrio dentro do novo contexto que se desenha na atualidade".

Esse equilíbrio se deve a ascensão do sexo feminino ao mercado de trabalho, cargos executivos, atuação em diversos seguimentos produtivos o que proporcionou mais independência, bem como a formação de nova mentalidade sobre o papel da mulher na sociedade. Porém, os paradigmas tradicionais ainda persistem em defini-la como inferiores em vários aspectos, quando a questão é analisada de alguns pontos de vista, principalmente aqueles que envolvem conteúdo conservador. Quanto aos outros aspectos, já mencionados, as mudanças de concepção ocorreram, e ocorrem, conforme os contextos e as demandas neles surgidas, pois são elas que definem os critérios de igualdade entre os gêneros. "A igualdade pressupõe um ordenamento a ser alcançado através de políticas de equidade, pois são essas que consideram as diferenças e presumem as identidades" (FIACHER E MARQUES, 2001, p. 07). Outros pontos que devem ser considerados estão relacionados com a classe a que pertence e a linhagem, ou seja, a classe a que pertence e a origem étnica, são 
também fatores substancialmente importantes a serem consideradas quando se analisa a questão da desigualdade entre os gêneros.

Em todo esse cipoal de ideologias, conceitos, concepções, fatores, aspectos, lutas, promoções ou construções encontram-se intencionalidades que apontam e justificam as concepções em que se ancoram as formas argumentativas de inferioridade. As lutas por políticas de equidade surgem a partir de propósitos ou de uma condição, seja ela econômica, social, de nascimento ou de cor e, que geralmente, denotam situações de exclusão.

$\mathrm{O}$ direito à igualdade de gênero tem sido, ao longo do tempo, tema de debate $\mathrm{e}$ discursão na sociedade, principalmente no mundo atual, defendido como direito fundamental, o que realmente é de fato. Sendo um direito fundamental é também um direito natural, partindo do princípio de que todos nascem iguais. Se a igualdade entre os gêneros for analisada por esse ângulo - do direito fundamental - podemos chegar à conclusão de que não deveria haver distinção entre os genros, pois todos nascem com os mesmos direitos, logo a lei deveria ser igual para todos, não apenas na teoria, mas também na pratica. Sendo assim, não seriam necessárias as lutas organizadas do gênero feminino para garantir algo que já é seu por direito. Segundo Fischer e Marques (2001, p. 08), "(...) a partir dos anos 80 as lutas femininas tomaram um novo rumo o que permitiu a formação de novo conceito para a causa das mulheres, o de gênero". Esse novo conceito, criado no intuito de fortalecer as lutas femininas, só foi possível graças ao ingresso, de forma mais intensa, das mulheres nos cursos universitários que permitiu a produção de estudos sobre o tema, os quais levaram a questão ao debate no meio acadêmico, dando maior visibilidade as lutas femininas.

Nesse sentido, é preciso entender que as leis são elaboradas conforme o processo de evolução da sociedade e a ideologia que orienta determinado contexto, atribuindo funções, papeis, estabelecendo normas e regras. Porém, as leis que regem a sociedade também tomam por base as tradições, e quebrar tradição não é tarefa fácil de se realizar, pois as mudanças radicais causam impactos nas estruturas culturais, politicas, conceituais ideológicas, sociais, principalmente se tiverem fundamentadas em valores religiosos. Por outro lado, as formas tradicionais são reforçadas pelo 
ideário popular, construído a partir de crendices e misticismo, ainda muito influentes na formação da consciência popular, nos tempos atuais.

As abordagens expostas reúnem argumentos que ajudam a entender as origens da desigualdade entre os gêneros. Sabe-se que as teorias são construídas para mudar conceitos dentro das necessidades de um novo contexto, criado ou surgido a partir de invenções tecnológicos, descobertas científicas, guerras ou catástrofe naturais. Esses contextos exigem processos de reestruturação para se adequar-se à nova realidade.

\section{RESISTENCIA DAS MULHERES ÀS DESIGUALDADES}

A luta das mulheres pela igualdade teve grande contribuição da ciência. Pesquisas revelaram que as mulheres têm capacidades iguais aos homens, nos mais variados aspectos. A difusão de tais estudos engrossou os movimentos feministas, organizações de classes entre outras, levando junto outros seguimentos sociais, também descriminados, como é o caso dos homossexuais e minorias afro descentes e indígenas. Segundo MMTR/RS (1999), foi constatado que desde a segunda metade do século XIX, as mulheres já faziam parte de movimento sociais, como é o caso da abolição da escravatura. No século XX, elas passaram a fazer parte de partidos políticos, mais tarde ingressaram na produção industrial e na luta contra a ditadura no período militar.

Junto com o surgimento dos movimentos sociais e, populares, muitas mulheres que viviam no campo tomaram a iniciativa de se organizar como forma de reivindicar seus direitos, como o "Movimento de Mulheres Agricultoras em Santa Catarina e a Organização de Mulheres da Roça no Rio Grande do Sul”, (MMTR/RS, 1999).

A organização dos movimentos fez surgir conferencias, nas quais foram elaborados documentos definindo políticas e programas que objetivavam diminuir as desigualdades entre homens e mulheres, através de medidas de combate às desigualdades. Os programas de ação resultantes de encontros e conferencias e dos reforços de órgãos internacionais como as Nações Unidas têm, ultimamente, obtido bons resultados, na medida em que os governos passaram a reconhecer a 
necessidade de definir políticas, especificamente direcionadas ao reconhecimento dos direitos de grupos discriminados e minorias.

O Brasil que sempre tratou mal parte de sua população, como os indígenas e seus descendentes, homossexuais, idosos, pobres, negros e mulheres, principalmente as que integram as classes média e baixa alcançou, ultimamente, grande avanço no combate às desigualdades, principalmente em relação às mulheres que vêm quebrando barreiras, rompendo tradições e conquistando espaços antes restritos aos homens. No entanto, não se pode dizer que tudo já foi resolvido, ainda há muito a fazer nesse longo percurso de lutas pela igualdade de gênero. Gebara (2001), ressalta que o feminismo tem como objetivo colocar o gênero feminino em equiparidade com o sexo masculino.

Por ser um país emergente, ou em desenvolvimento, e aspirante ao grupo dos países desenvolvidos o Brasil busca frequentemente modernizar sua legislação com textos extensos e cheios de lacunas, espaços vazios e difíceis de serem cumpridos, pois sempre são outorgas que a maioria da população desconhece, não entendem, de difícil interpretação e, portanto, sem muito efeito prático. De acordo com Frei Beto (2001), sob pressão, a Organização das Nações Unidas (ONU) declarou o Ano Internacional da Mulher, em 1975, e na mesma década e nos anos de 1980, inaugurou o que seria a Década da Mulher, declarado em todo mundo.

Os avanços na legislação, em prol da igualdade de direitos e na garantia de sua defesa, em relação às questões de desigualdade entre os diversos seguimentos sociais, e, em especial entre os gêneros são conquistas extremamente importantes e até certo ponto imensurável aos olhares dos excluídos. Porém, há fatores, além dos vários já mencionados, que implicam diretamente e com impacto na aplicação e observação das leis e no seu reconhecimento que são os fatores educacional, étnico, social, religioso, econômico. 


\section{A EDUCAÇÃO COMO ELEMENTO DE RESISTENCIA A IGUALDADE DE GÊNERO}

A educação, oferecida de forma gratuita e obrigatória a sociedade brasileira, ainda não contempla um modelo educacional genuinamente nacional, há sempre algum elemento resultante de cópias externas além, é claro, do abismo que se formou entre a educação e as mudanças processadas no contexto da evolução tecnológica e das descobertas cientificas, ocorridas nas últimas décadas. Dessa forma, tem como resultado uma educação deficiente que forma cidadãos com deficiência intelectual, incapazes de promover mudanças que levem às transformações tão requeridas pela sociedade.

De acordo com Oliveira (2001), ainda que escola e os movimentos sociais ensinem de forma pacífica ambos têm de habitual o sentido político do processo educacional, tanto a escola como os movimentos sociais, na opinião da autora, devem ser lugares favoráveis ao desenvolvimento de uma educação crítica, emancipatória. Entende-se, portanto, que o verdadeiro papel da escola e dos movimentos que mobilizam a sociedade, por uma determinada causa, deve contribuir, fundamentalmente para a construção de conhecimentos fundamentais as transformações sociais de equidade, de uma sociedade mais justa e fraterna.

Conforme Fischer e Marques (2001, p. 07-08) "A educação, seja a informal doméstica, seja a instrução escolar, se constitui numa das bases da exclusão e da violência contra o feminino, disseminada em vários contextos da sociedade (...)". Sendo assim, é preciso avançar, preferencialmente na formação intelectual (pesquisa e extensão) para que uma mobilização popular associada ao engajamento da luta pela desmistificação de estereótipos e quebra de preconceitos, esvaziamento de conceitos e concepções tradicionais que atuam desfavoravelmente no processo educativo. Paulo Freire (1989), em suas análises sobre a questão educacional, referente à formação do sujeito, nos ensina que o verdadeiro sentido da educação é contribuir para que o oprimido possa lutar pela transformação da realidade, isto é, libertar-se da condição de oprimido. 
As instituições educacionais ainda oferecem em seus currículos elementos, recheados de conteúdos preconceituosos, que reforçam os ideais de hegemonia masculina, fruto do patriarcalismo, tradicionalmente construído no contexto medieval e aceito como modelo de sociedade. Isso, grosso modo, contribui direta ou indiretamente para a perpetuação do ideário que concebe a desigualdade entre os gêneros como uma normalidade natural.

Por outro lado, há, com grande frequência e repercussão, a veiculação de conteúdos nos principais instrumentos de comunicação e informação que também reforçam as ideias de inferioridade do sexo feminino, preservado culturalmente, expressos nos meios de comunicação em massa, indústria cinematográfica, novelas entre outros. $A$ intenção desses veículos de comunicação e informação, talvez não seja a de reforçar esses conceitos ou ideias que levam aos processos discriminatórios, o que se questiona é a dificuldade ou incapacidade da maioria dos telespectadores, usuários, ouvintes ou internautas em absorver, digerir, entender e interpretar o verdadeiro sentido que expressam esses conteúdos veiculados pela televisão, jornal, internet e redes sociais.

A deficiência do sistema educacional não corresponde as demandas que emergem da sociedade, no que concerne as necessidades que requer o contexto no qual se processam as informações, isto é, uma sociedade desinformada na era da informação. As políticas educacionais oferecidas pelo Estado obstaculariza os processos de mudanças e transformações, sejam elas em que plano for, principalmente nas esferas das mudanças de concepções e na formação de novos conceitos sobre intolerância, discriminação e preconceitos, concernente a igualdade entre os gêneros. Conte (2008, p. 04) afirma o seguinte: "É através da opressão e da exploração sofridas no cotidiano, e encontrando formas de reação, através da subversão, especialmente, coletiva, que se possibilita às mulheres, libertação e autoestima". O exposto acima reforça a ideia de que as formas de opressão podem servir de estímulo aos movimentos de resistência, a partir do desenvolvimento da formação crítica através de uma educação emancipatória. 
A luta das mulheres pela garantia e reconhecimento de seus direitos encontrou, e continua encontrando, forte resistência, o que não podia ser diferente, diante de uma sociedade machista e excludente. Algumas das conquistas alcançadas pelo sexo feminino, à custa de muitos esforços, às vezes até com perdas de vidas nem sempre são respeitadas. As agressões, maus tratos, discriminação, feminicídio e preconceito continuam, não fosse isso existem ainda as ameaças, que na maioria das vezes, impede a aplicação da lei e, consequentemente anulam todos os direitos conquistados ou mesmo adquiridos. A deficiência na formação educacional dificulta a evolução de processos que ofereçam subsídios intelectuais para a construção de conhecimentos que permitam reconhecer a igualdade de direitos entre os gêneros, sem distinção de gênero, origem étnica, sexo, cor, credo religioso e condição financeira.

\section{TRABALHO, UMA QUESTÃO DE EXTREMO DESRESPEITO}

Os movimentos feministas de resistência e busca por igualdade de direitos já teve resultados positivos no âmbito da legislação, como a definição de políticas que objetivam promover, ativamente a eliminação das formas de discriminação e exclusão sobre os direitos das mulheres e desenvolver ações de apoio à participação feminina nas tomadas de decisões do país. Conforme Fischer e Marques (2001, p. 05), "a exclusão da mulher [no trabalho] não encontra explicações nas conjunturas econômicas". Para as autoras, a hierarquia do patriarcado mantém a mulher numa condição de inferioridade atribuindo-Ihe funções de trabalho gratuito o que, segundo elas, é de "grande relevância para a sociedade pensada para o homem" (FISCHER e MARQUES, 2001, p. 05).

Nesse contexto, vale ressaltar o que diz respeito à violência e o assédio sexual, que talvez, sejam os mais difíceis de serem combatidos ou eliminados, pelo fato de ocorrerem no recinto doméstico e no trabalho. "No caso do Brasil, a violência exercida contra a mulher tem se constituído em preocupação de pesquisadores e pesquisadoras, juntamente com a luta pelo direito à cidadania nos âmbitos jurídico, educacional, sexual e econômico..." (FISCHER E MARQUES, 2001, p. 06). A violência, manifestada em várias formas é um problema enfrentado diariamente pelas mulheres, onde os mais frequentes são as agressões domésticas e o assédio sexual. 
As agressões acompanhadas de ameaças, chantagens e indiferença coloca o agressor em posição privilegiada em relação a vítima, que muitas vezes, acaba se calando diante da situação. Isso ocorre devido a vários motivos, entre os quais destaca-se o medo de perder o trabalho, dependência financeira, em função dos baixos salários, medo de escandalizar a família, principalmente os filhos, quando há e a reputação como mulher e represálias.

Fischer e Marques (2001, p. 05), salientam que: "A lógica da globalização e das cadeias produtivas, muito oportunas para o capitalismo contemporâneo, incorporou os bolsões mundiais de trabalho barato, sem necessariamente elevar-Ihe a renda (...)". Nesse sentido, a questão salarial é um dos fatores de maior opressão atribuídos ao sexo feminino, sendo que o salário pago ao trabalho realizado pelas mulheres segue a lógica do tratamento dado ao gênero: inferior.

Nesse contexto, estão ainda as questões relativas, especificamente ao trabalho, no que se refere à questão salarial, onde segundo estudos, grande parte das mulheres assalariadas recebem valores menores que o sexo masculino, realizando as mesmas atividades. A participação das mulheres no mercado de trabalho é menor que a dos homens. Isso reflete o acentuado nível de pobreza, verificado nas camadas menos favorecidas da população.

\section{O FEMINISMO EM BUSCA DA IGUALDADE E ALGUNS ASPECTOS DA LEGISLAÇÃO}

As abordagens sobre a igualdade de gênero, a adoção de medidas e políticas no combate às desigualdades e a atenção especial dos organismos governamentais à causa das mulheres torna-se um imperativo, na medida em que, as ações definidas, estrategicamente sobre a questão feminista, ainda não garantiram, efetivamente, mudanças significativas nos processos discriminatórios contra as mulheres, principalmente das classes menos favorecidas, afrodescendente e de origem indígena. Assim, a luta pela ampliação dos direitos ainda está muito longe de se concretizar de fato e equiparar-se aos do sexo masculino. 
Nessa perspectiva, vale ressaltar que os direitos de igualdade já estão garantidos em lei, o problema é a observação dessas leis que, no caso do Brasil, precisam ser reforçadas por outras leis. A Declaração Universal dos Direitos Humanos, adotada pela ONU (Organização das Nações Unidas), estabelece em seu artigo $2^{\circ}$. que:

Todos os seres humanos podem invocar os direitos e as liberdades proclamadas e presentes nessa Declaração, sem distinção alguma, nomeadamente de raça, de cor, de sexo, de língua, de religião, de opinião política ou outra de origem nacional ou social, de fortuna, de nascimento ou de qualquer outra situação. Além disso, não será feita nenhuma distinção fundada no estatuto político, jurídico ou internacional do país ou do território da naturalidade da pessoa, seja esse país ou território independente, sob tutela, autônomo ou sujeito a alguma limitação de soberania, (DECLARAÇÃO UNIVERSAL DOS DIREITOS HUMANOS, 2009, p. 5).

O texto do artigo foi, ao longo do tempo, ampliado e reforçado de forma distinta pelas conferencias realizadas, nas décadas de 70 e 80 e principalmente na década de 90 , quando seus efeitos foram aprovados pela Assembleia Geral da ONU. Diante do processo de exclusão das minorias, especialmente o sexo feminino, tornaram-se iniciativas capazes de conter as ações discriminatórias e afastar os diversos empecilhos que agem desfavoravelmente contra a igualdade entre os gêneros. $O$ texto, da Declaração Universal dos Direitos Humanos, não cita seguimentos, classes ou grupo sociais específicos, não faz distinção, ou seja, se a lei fosse observada e tomada como modelo entre os povos facilitaria às sociedades romper com os estereótipos e coibir as formas discriminatórias que inferiorizam o gênero feminino.

As deliberações, em definir papeis e atribuir funções aos gêneros, são características das sociedades hierarquizadas que conservam valores socialmente aceitos e preservados. São comportamentos construídos e repassados de geração a geração e, portanto, difíceis de serem eliminados, pois são tradições imbricadas ideologicamente na formação da mentalidade popular.

Não obstante, a questão da igualdade entre os gêneros, precisa considerar qual modelo o estado, território, país ou grupos sociais está organizado ou estruturado dentro do contexto mundial. No caso do Brasil, contido no sistema capitalista, a 
igualdade entre os gêneros não será superada tão facilmente, pois as características do referido sistema impedem que tal situação possa ocorrer. No sistema capitalista a desigualdade é uma das suas principais características. Sendo assim, a construção da igualdade, no referido sistema, jamais poderá ser concretizada, poderá até ser amenizada ou aliviada, mas nunca superada totalmente. Nesse sentido, Meszaros (2002), argumenta que a igualdade entre homens e mulheres, classes ou grupos sociais é impossível no sistema capitalista.

Vendo por essa ótica, a possibilidade de igualdade torna-se difícil de ser concretizada, resta apenas a utopia que alimenta as lutas e o sonho da igualdade. Isso nos permite entender que as leis, programas e ações, proclamadas pelos órgãos internacionais, como a ONU, ou mesmo por legislações nacionais não são cumpridas, pois, sendo órgãos ou organismos a serviço do capitalismo, os países sabem que suas proposições são inviáveis.

Sabe-se que nas últimas décadas houve várias conquistas e significativo empenho dos governos, entidades e instituições e, podemos citar o Brasil, em atender as reivindicações dos movimentos feministas, sendo que o poder público se mostrou disposto a debater sobre a questão da igualdade entre os gêneros, só que numa agenda onde a pauta não tem muita prioridade. Os legisladores argumentam que os debates precisam amadurecer e, que, as discursões devem passar por uma apreciação mais minuciosa para não correr o risco de precipitação e cometer equívocos.

A Constituição Brasileira de 1988, no seu artigo 5o, estabelece o princípio da igualdade, quando determina que: "Todos são iguais perante a lei, sem distinção de qualquer natureza e que é garantido o direito à vida, a liberdade, a igualdade, a segurança e propriedade" (BRASIL, 2004, p. 7).

Percebe-se que, o exposto acima estabelece a igualdade de todos sem nenhuma distinção, mas diante da realidade questiona-se: Se todos são realmente iguais porque existem os excluídos? Por que então temos os movimentos de classe, os movimentos feministas lutando em busca de igualdade? Essas são questões que 
soam, pois teoricamente a lei estabelece todas as garantias, as ideologias que orientam a prática são antagônicas à legislação.

De acordo com a Constituição, o seu artigo $3^{\circ}$, determina como objetivo fundamental: "Promover o bem de todos, sem origem, preconceito de origem, raça, sexo, cor, idade e quaisquer outras formas de discriminação" (BRASIL, 2004, p. 31).

A legislação expressa claramente a igualdade assegurando o legitimo direito, estendendo-o a todos sem distinção. Isso remete a uma reflexão acerca do que deveria ser essa igualdade sem distinção e acerca das desigualdades, bem como o processo de superação, através das lutas de classes e, em espacial, os movimentos feministas. O fato de a igualdade existir em lei, de forma legal, não quer dizer que ela seja de fato assegurada a todos como prevista, fosse assim, não haveria os movimentos que buscam conquistar a liberdade em sua plenitude.

Os movimentos feministas já obtiveram conquistas importantes no Brasil, como é o caso da Lei Maria da Penha, importante instrumento de combate à desigualdade e, substancialmente importante nesse processo de luta pela superação das desigualdades, das agressões e do desrespeito a que as mulheres são submetidas em nossa sociedade. A Lei Maria da Penha veio reforçar o que determina o artigo 5o, da Constituição Federal. Sancionada em 2006, a Lei Maria da Penha estabeleceu mudanças no contexto da realidade das mulheres e propôs o aumento do rigor referente às punições aplicadas às agressões, maus tratos e desrespeito as mulheres.

As mulheres estiveram presentes em quase todos os grandes momentos que marcaram a história do Brasil, mas foi nas últimas décadas que de fato começaram a ser reconhecidas no país como personalidades importantes na construção da sociedade. Isso porque nas últimas décadas foram destaques nas competições esportivas nacionais e internacionais, na música, na arte, na política, nas atividades produtivas, nas ciências e, sobretudo, na educação o que thes deu maior visibilidade na luta pela igualdade. 
A última década do século $X X$ e o início do século $X X I$, culminaram com a chamada era do conhecimento, em face da evolução técnico-cientifica, o avanço tecnológico, a tecnologia da informação e comunicação, acessadas pelos dispositivos móveis conectados à internet, as redes sociais e da consolidação do processo de globalização abalaram as estruturas patriarcais e viabilizaram o surgimento de movimentos cada vez mais organizados contra o patriarcalismo e contra os atos de discriminação e preconceito contra a mulher.

\section{CONSIDERAÇÕES FINAIS}

Pelo exposto acima, conclui-se que as relações de igualdade entre os gêneros ainda são orientadas pelas concepções tradicionais, embora os movimentos de resistência e a construção de novas relações tenham avançado nas últimas décadas a mentalidade machista ainda persiste em classificar o gênero feminino com inferior. Porém, os movimentos feministas ganharam expressividade na conquista de espaços, reconhecimento e atribuindo repúdio as práticas tradicionais que obstaculariza o processo de igualdade. A luta das mulheres demonstra o encorajamento no combate à discriminação na busca para a construção de uma nova sociedade, onde o enfrentamento das questões de interesses de classes e de gênero sejam pautadas de forma que contemplem todos de forma menos desigual.

Constatou-se que não é tarefa fácil mudar uma realidade, um contexto já consolidado e sedimentado com ideias, hábitos, costumes, atitudes e comportamentos historicamente construídos e socialmente aceitos, valorizados e reproduzidos pelas sociedades ao longo dos tempos, no entanto os avanços tecnológicos na informação e comunicação, a globalização, o processo produtivo tornam o ambiente favorável as mudanças nas relações sociais e na formação de novas concepções sobre a igualdade entre os gêneros.

Sabe-se que, a plena igualdade de gêneros não será possível enquanto o atual modelo de sociedade, de economia e de política ditarem as regras e as normas que orientam a vida em sociedade. A persistência da desigualdade evidencia que é preciso desenvolver mais iniciativas, as lutas feministas têm se mostrado eficientes, mas 
pouco efetivas do ponto vista institucional. Ainda é notório o processo de exclusão e discriminação por parte do gênero masculino, seja por herança ideológica ou por questões de natureza física, étnica, econômica e social.

Entrementes, para que haja de fato igualdade entre os gêneros é preciso construir novas bases para a formação de uma nova sociedade, despida de processos discriminatórios, ideologias, costumes, concepções opressoras e construir novos conhecimentos que conceba os seres humanos como iguais em todos os âmbitos da vida. Espera-se que este estudo possa contribuir com novas reflexões e que novos olhares se voltem para a problemática da desigualdade entre os gêneros, a fim de apontar caminhos e possibilidade para conter as desigualdades associados a intensificação dos movimentos para conquista de novos espaços e acessos, a participação nas tomadas de decisões e o reconhecimento dos direitos dos que se encontram em estado de opressão.

\section{REFERENCIAS}

ANTUNES, R. Os sentidos do trabalho: ensaio sobre a afirmação e a negação do trabalho. São Paulo: Boitempo, 1999.

BRASIL. Senado Federal. Comissão Temporária Interna "Ano da Mulher-2004". A mulher e as leis: perguntas e respostas para o Brasil do século XXI. Brasília: Secretaria Especial de Editoração e Publicações, 2004.

. Lei Maria da Penha: cartilha informativa sobre a lei № 11.340 de 2006. Brasília: Centro de documentação e informação. Coordenação de Publicações, 2007.

CONTE, Isaura Isabel. Mulheres feministas e camponesas? Revista eletrônica Espaço da Sophia. Vol. 15, ano II, Junho/2008.

Declaração Universal dos Direitos Humanos, 2009. Disponível em: http://www.un.org/>. Acessado em 15/06/2020. 
DUQUE, L.V. Abrigos e albergues para moradores de rua: uma realidade em questão. Porto Alegre: [s. n.], 2000.

FISCHER, I.R.; MARQUES, F. Gênero e exclusão social. Trabalho para discussão 112, agosto/2001.

FREI BETTO. A Marca do Batom. São Paulo, agosto de 2001.

FREIRE, Paulo. Pedagogia do oprimido. - ed. 23ª - Rio de Janeiro: Paz e Terra, 1989.

GEBARA, Ivone. Cultura e relações de gêneros. São Paulo: Cepis, 2001.

MESZAROS, István. Para além do capital. São Paulo: Bomtempo, 2002.

MMTR/RS. A evolução da mulher na humanidade. Textos internos. Passo Fundo, RS: [s.n.], 1995.

As mulheres na luta. Textos internos. Passo Fundo, RS: [s.n.], 1999.

OLIVEIRA, Elizabeth Serra. Movimentos sociais e educação popular no Brasil urbano industrial - UFF/ GT: Movimentos Sociais e Educação / n.03.

PAÑUELOS. Hacia una pedagogia feminista: gêneros e educación popular. Bueno Aires: América Libre, 2007.

Enviado: Julho, 2020.

Aprovado: Novembro, 2020. 